\title{
Heterogeneous Nb-Based Nuclei for the Grain Refinement of Al-Si Alloys
}

\author{
L. BOLZONI ${ }^{1,2,3}$ and N. HARI BABU ${ }^{2}$ \\ 1.-Waikato Centre for Advanced Materials (WaiCAM), The University of Waikato, Private Bag \\ 3105, Hamilton 3240, New Zealand. 2.-Institute of Materials and Manufacturing, Brunel Uni- \\ versity London, Uxbridge, Middlesex UB8 3PH, UK. 3.—e-mail: bolzoni.leandro@gmail.com
}

\begin{abstract}
$\mathrm{Nb}$-based intermetallics are, generally, low-density high-temperature materials used for structural applications or cryogenic superconductors. In this work, we report the development of an $\mathrm{Al}(96)-\mathrm{Nb}(2)-\mathrm{B}(2)$ master alloy where in situ-formed micrometric $\mathrm{Nb}$-based intermetallics (i.e. $\mathrm{NbB}_{2}$ and $\mathrm{Al}_{3} \mathrm{Nb}$ ) are used for a completely different purpose: to promote the refinement of $\mathrm{Al}-\mathrm{Si}$ alloys by taking advantage of enhanced heterogeneous nucleation. Nb-based intermetallics have the right characteristics, like low density, stability at high temperature and good lattice match, to be used as heterogeneous nucleation substrates. It was found that the addition of these Nb-based intermetallics permits the significant refinement of the microstructural features of the $\mathrm{Al}-\mathrm{Si}$ alloy studied. The enhanced heterogeneous nucleation makes the grain size of the material far less dependent on the cooling rate, which is one of the critical parameters influencing the variation of the properties of the alloy.
\end{abstract}

\section{INTRODUCTION}

Niobium is a transition metal characterized by some specific properties such as superconductivity at the cryogenic temperature of $9.2 \mathrm{~K}$. Due to its outermost electronic configuration, niobium is able to form different compounds. The two most common $\mathrm{Nb}$-based intermetallics are probably, niobium borides and niobium aluminides. Specifically, $\mathrm{NbB}_{2}$ has been extensively studied and it has been reported that it exhibits superconductive transition behaviour depending on the stoichiometry of the compound. ${ }^{1-3}$ Niobium aluminides, specifically $\mathrm{Al}_{3} \mathrm{Nb}$, were developed due to promising attributes for hightemperature applications such as high melting point and low density, ${ }^{4,5}$ high strength over a wide range of temperatures and good oxidation resistance. These properties made them strong candidates for advanced aeropropulsion systems and for other high-temperature components, either as a coating or as structural materials. Two of the previously mentioned aspects (i.e. high-temperature stability and low density) are fundamental prerequisites for the development of potential heterogeneous nucleation substrates for aluminium alloys, characteristics which should be coupled with good lattice match between the structure of the substrate and the nucleating phase. The most common example of heterogeneous nucleation substrates added to a molten metal to promote the heterogeneous nucleation and, thus, the refinement of its microstructure is the addition of Al-Ti-B master alloys to $\mathrm{Al}$ and wrought $\mathrm{Al}$ alloys. ${ }^{6-9}$ These master alloys are composed of Ti-based compounds (i.e. $\mathrm{TiB}_{2}$ and $\mathrm{Al}_{3} \mathrm{Ti}$ ), and it is believed that nucleation is promoted because $\mathrm{TiB}_{2}$ acts as the actual heterogeneous nucleation site, on top of which a thin atomic-scale layer of $\mathrm{Al}_{3} \mathrm{Ti}$ is formed to reduce and accommodate the lattice strain. ${ }^{10,11}$ This is because the lattice mismatch between $\mathrm{Al}$ and $\mathrm{Al}_{3} \mathrm{Ti}$ is lower than that between $\mathrm{Al}$ and $\mathrm{TiB}_{2}{ }^{12}$ Nevertheless, $\mathrm{Al}-\mathrm{Ti}-\mathrm{B}$ master alloys are not extensively used in the case of cast $\mathrm{Al}-\mathrm{Si}$ alloys because titanium and silicon react between themselves hindering the efficient refinement of the alloy (this occurrence is known as $\mathrm{Si}$ poisoning). ${ }^{13,14}$ Based on the promising characteristics of the $\mathrm{Nb}$-based intermetallics (i.e. $\mathrm{NbB}_{2}$ and $\mathrm{Al}_{3} \mathrm{Nb}$ ), we analysed crystallographic databases and found that $\mathrm{Nb}$-based intermetallics, which have an isomorphous structure and similar lattice parameters to the respective Ti-based compounds, would be successful candidates as heterogeneous nucleation substrates for Al-Si alloys. ${ }^{15}$ In our first works, ${ }^{16,17}$ in which the Nb-based intermetallics were formed 
by adding $\mathrm{Nb}$ powder and $\mathrm{KBF}_{4}$ flux to Al-Si alloys, we demonstrated the grain refining potency of $\mathrm{Nb}$ based intermetallics on Al-Si alloys. The grain refinement is not hindered even though niobium can form silicides, as these intermetallic phases are stable at much higher temperatures with respect to their Ti-based counterparts. This means that their kinetics are much slower, in particular at processing temperatures typically used in $\mathrm{Al}$ foundries, and, thus, no poisoning was detected. ${ }^{16,17}$ In this work, we focused on the development of an $\mathrm{Al}(96)$ $\mathrm{Nb}(2)-\mathrm{B}(2)$ master alloy, which has been found to be easier to add to the melt, starting from a different source of raw materials [i.e. $\mathrm{Nb}$ powder and $\mathrm{Al}(95)$ $\mathrm{B}(5)$ master alloy]. The aim of this work is to report and discuss the employment of the (in situ-formed micrometrics) Nb-based intermetallics for an alternative application rather than as a structural material. Specifically, the grain refining effectiveness of the Nb-based intermetallics is assessed on an Al-Si casting alloy solidified using different cooling rates.

\section{MATERIALS AND METHODS}

The raw materials employed in this study are (values given refer to the weight of the elements except where otherwise stated): pure aluminium (purity >99.5), niobium powder (purity >99.8), $\mathrm{Al}(95)-\mathrm{B}(5)$ master alloy and a hypoeutectic Al-Si alloy (Al-8.4Si-0.3Mg-0.13Fe). The required amounts of aluminium, niobium and $\mathrm{Al}(95)-\mathrm{B}(5)$ were prepared in order to fabricate an $\mathrm{Al}(96)-\mathrm{Nb}(2)-\mathrm{B}(2)$ master alloy. Aluminium was melted at $1063 \mathrm{~K}\left(790^{\circ} \mathrm{C}\right)$ for $3.6 \mathrm{ks}$ (i.e. $1 \mathrm{~h}$ ) and, subsequently, the $\mathrm{Al}(95)-\mathrm{B}(5)$ master alloy was added to the melt and the temperature was increased to $1123 \mathrm{~K}\left(850^{\circ} \mathrm{C}\right)$. After $3.6 \mathrm{ks}(1 \mathrm{~h})$ at $1123 \mathrm{~K}\left(850^{\circ} \mathrm{C}\right)$, niobium powder was added and left to dissolve for $7.2 \mathrm{ks}(2 \mathrm{~h})$ with intermediate stirring. The microstructure of the $\mathrm{Al}(96)-\mathrm{Nb}(2)-\mathrm{B}(2)$ master alloy was analysed using optical and scanning electron microscopy (SEM). Understanding the fundamental effect of the addition of $\mathrm{Nb}$-based intermetallics on the solidification behaviour was assessed by means of thermal analysis (i.e. recording the cooling curves using K-type thermocouples). For consistency, the same setup was used for all the undercooling experiments in which the thermocouple was placed in the middle of the 10-cm-diameter crucible at a height of $5 \mathrm{~cm}$ from the bottom of the crucible. For the grain refining experiments, $5 \%$ of $\mathrm{Al}(96)-\mathrm{Nb}(2)-\mathrm{B}(2)$ master alloy (equivalent to $0.1 \%$ of $\mathrm{Nb}$ ) was added to the $\mathrm{Al}-$ $8.4 \mathrm{Si}-0.3 \mathrm{Mg}-0.13 \mathrm{Fe}$ alloy melted at $1063 \mathrm{~K}\left(790^{\circ} \mathrm{C}\right)$ and left in contact with the melt for $1.8 \mathrm{ks}$ (i.e. $30 \mathrm{~min}$ ). Afterwards, the alloy was left to cool and poured from a temperature of $1013 \pm 3 \mathrm{~K}\left(740 \pm 3^{\circ} \mathrm{C}\right)$. Reference samples (without the addition of any master alloy) were also cast under the same processing conditions for the sake of comparison. In order to simulate the cooling conditions of many industrial processes and, thus, to solidify the alloy under a varying range of cooling rates, a wedge-shaped (copper) mould and a cylindrical (steel) mould were used. Characterisation was performed at both macro- and micro-level. Macrovisual analysis gave a first insight of the effect of the addition of the grain refinement whereas the microstructural analysis permitted the quantification of the grain size reduction as well as the effect of the addition of $\mathrm{Nb}$-based intermetallics on the other microstructural features. Macro- and micro-etching (i.e. anodising for grain size measurements) were performed, respectively, by means of Tucker's and Barker's solutions. The analysis of the microstructures was conducted using a Carl Zeiss Axioskop 2 MAT optical microscope and the linear intercept method was used to determine grain sizes.

\section{RESULTS AND DISCUSSION}

\section{Characterisation of the $\mathrm{Al}(96)-\mathrm{Nb}(2)-\mathrm{B}(2)$ Master Alloy}

Once produced, the $\mathrm{Al}(96)-\mathrm{Nb}(2)-\mathrm{B}(2)$ master alloy was sectioned and analysed in order to confirm the formation and presence of, as well as to characterise, the (Nb-based) intermetallic compounds. Optical microscopy revealed that the $\mathrm{Al}(96)-\mathrm{Nb}(2)$ $\mathrm{B}(2)$ master alloy has a rather uniform distribution of intermetallic phases dispersed and embedded in the aluminium matrix as can be seen in Fig. 1a. Moreover, it indicated that there were at least two different types of intermetallics which differ in both colour and size, the black ones being larger than the dark grey ones.

Examining the master alloy with the SEM permitted the confirmation of the formation and nature of the $\mathrm{Nb}$-based intermetallics (i.e. $\mathrm{NbB}_{2}$ and $\mathrm{Al}_{3} \mathrm{Nb}$ ) due to the reaction of niobium with boron or aluminium, respectively (see Fig. 1b). Furthermore, it was found that aluminium borides (with nonstoichiometric composition $\mathrm{AlB}_{x}$, where $x=2-12$ on the basis of the semi-quantitative EDS chemical analysis) were also present. They are thought to derive from the employment of the $\mathrm{Al}(95)-\mathrm{B}(5)$ master alloy used as a source of boron because of their less favourable enthalpy of formation in comparison to niobium borides. ${ }^{18}$ Nonetheless, it is also possible that some of them may have formed during the fabrication of the $\mathrm{Al}(96)-\mathrm{Nb}(2)-\mathrm{B}(2)$ master alloy. Although aluminium borides $\left(\mathrm{AlB}_{\mathrm{x}}\right)$ have some refining effect on $\mathrm{Al}-\mathrm{Si}$ alloys, their performance is limited if titanium is present as an impurity in the alloy. ${ }^{19}$ This is because aluminium borides tend to transform to titanium borides due to the greater stability of the latter. The Al-Si alloy considered in this study has a relatively high titanium impurity level $(\sim 0.1)$ and, therefore, the great majority of $\mathrm{AlB}_{x}$ will transform to Ti-borides, which cause Si poisoning. Consequently, the refining effect of aluminium borides $\left(\mathrm{AlB}_{x}\right)$ and Tiborides on the performances of the $\mathrm{Al}(96)-\mathrm{Nb}(2)$ $\mathrm{B}(2)$ master alloy can be ignored. 

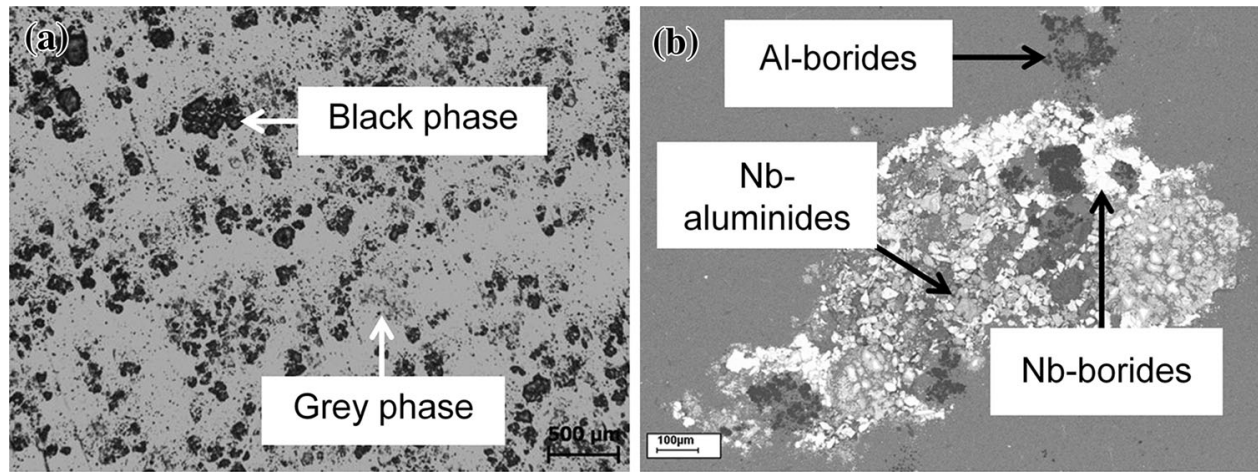

Fig. 1. Details of the nature and distribution of the intermetallic particles present in the $\mathrm{Al}(96)-\mathrm{Nb}(2)-\mathrm{B}(2)$ master alloy: (a) bright field optical micrograph and (b) SEM picture.
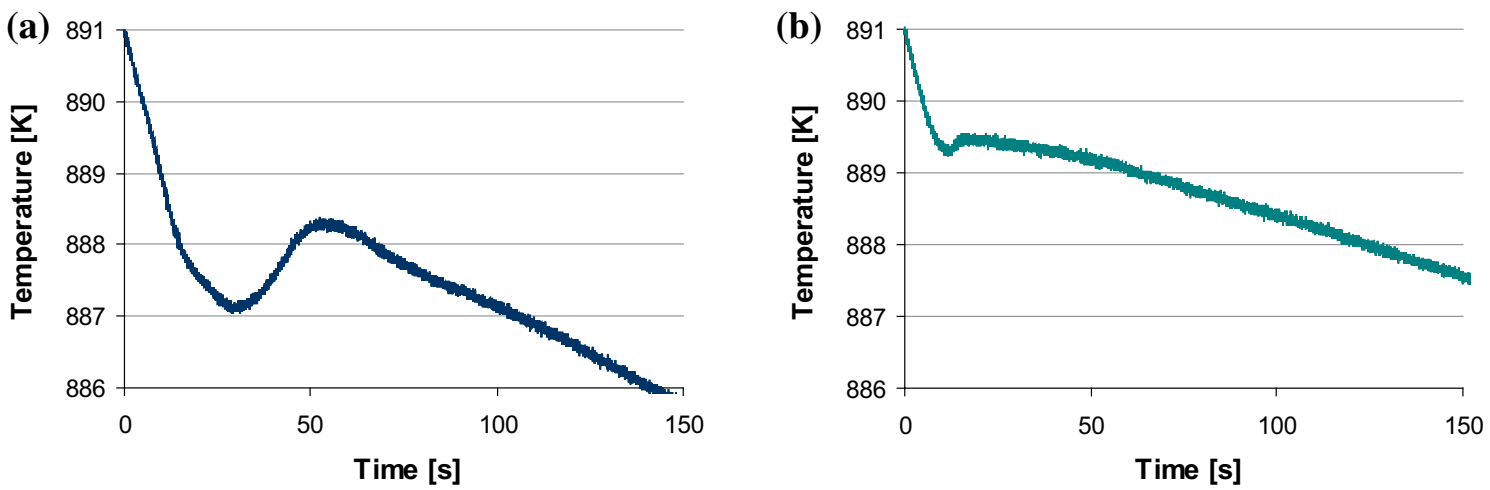

Fig. 2. Thermal analysis of the Al-Si alloy without (a) and with (b) the addition of the Al(96)- $\mathrm{Nb}(2)-\mathrm{B}(2)$ master alloy.

\section{Fundamental Effect of Nb-Based Intermetallics on Nucleation}

Thermal analysis, i.e. the measurement of the cooling curve during the solidification of a metal, has been proposed and used as an estimation of the effect of the addition of heterogeneous nucleation substrates and, thus, the effectiveness of a grain refiner. ${ }^{20,21}$ The solidification curve of the $\mathrm{Al}-\mathrm{Si}$ alloy considered in this study (reference) is the classical solidification curve with a valley, whose minimum and recalescence temperatures are 887.0 $\mathrm{K}\left(614.0^{\circ} \mathrm{C}\right)$ and $888.4 \mathrm{~K}\left(615.4^{\circ} \mathrm{C}\right)$, as can be seen in Fig. 2. The undercooling $(\Delta T)$ needed for aluminium atoms to group into clusters and form stable nuclei which subsequently grow into grains is the difference between the two previously mentioned temperatures which, therefore, equals $1.4 \mathrm{~K}$ (see Table I).

As can be seen in Fig. 2b, the introduction of the $\mathrm{Nb}$-based intermetallic particles displaces the cooling curve to a higher temperature, which can be expected when grain refiners are added. ${ }^{20,22,23}$ From the analysis of the cooling curves (data reported in Table I), it can be seen that the addition of the $\mathrm{Al}(96)-\mathrm{Nb}(2)-\mathrm{B}(2)$ master alloy induces the reduction of the undercooling from $1.4 \mathrm{~K}$ to $0.3 \mathrm{~K}$. The reduction of the energy barrier needed for the nucleation of the $\alpha$-Al grains confirms the hypothesis that the Nb-based intermetallics are good potent heterogeneous nucleation sites for the nucleation and growth of aluminium grains. Thermal analysis was carried out with the aim of understanding the effect of $\mathrm{Nb}$-based intermetallic particles and a reduction was expected on the basis of the interrelationship which exists between the lattice mismatch parameter $(f)$ and the undercooling ( $\Delta T=\alpha \cdot f$, where $\alpha$ is a variable that depends on physical properties such as heat of fusion, molar volume of crystals, etc.). ${ }^{24}$ It is worth recalling that the fact that $\mathrm{Nb}$-based intermetallics have good lattice match with the $\mathrm{Al}$ nucleating phase was one of the reasons why the $\mathrm{Al}(96)-\mathrm{Nb}(2)-\mathrm{B}(2)$ master alloy was developed.

\section{Assessment of the Effect of Nb-Based Intermetallics on Microstructural Features}

As just explained, the reduction of the undercooling confirmed that enhanced heterogeneous nucleation is the main solidification mechanism and, consequently, because of the greater number of nucleation events, a reduction in the final grain size is expected. The comparison of the results of the microstructural analysis of the Al-Si alloy without (Fig. 3) and with the addition of the 
Table I. Results of the analysis of the cooling curves shown in Fig. 2

\begin{tabular}{|c|c|c|c|}
\hline Material & $\begin{array}{c}\text { Valley minimum } \\
\text { temperature }\left[\mathrm{K}\left({ }^{\circ} \mathrm{C}\right)\right] \\
\end{array}$ & $\begin{array}{c}\text { Valley maximum } \\
\text { temperature }\left[K\left({ }^{\circ} \mathrm{C}\right)\right]\end{array}$ & $\Delta \boldsymbol{T}(\mathbf{K})$ \\
\hline $\begin{array}{l}\text { Reference } \\
\mathrm{Al}(96)-\mathrm{Nb}(2)-\mathrm{B}(2) \text { master alloy addition }\end{array}$ & $\begin{array}{l}887.0(614.0) \\
889.3(616.3)\end{array}$ & $\begin{array}{l}888.4(615.4) \\
889.6(616.6)\end{array}$ & $\begin{array}{l}1.4 \\
0.3\end{array}$ \\
\hline
\end{tabular}

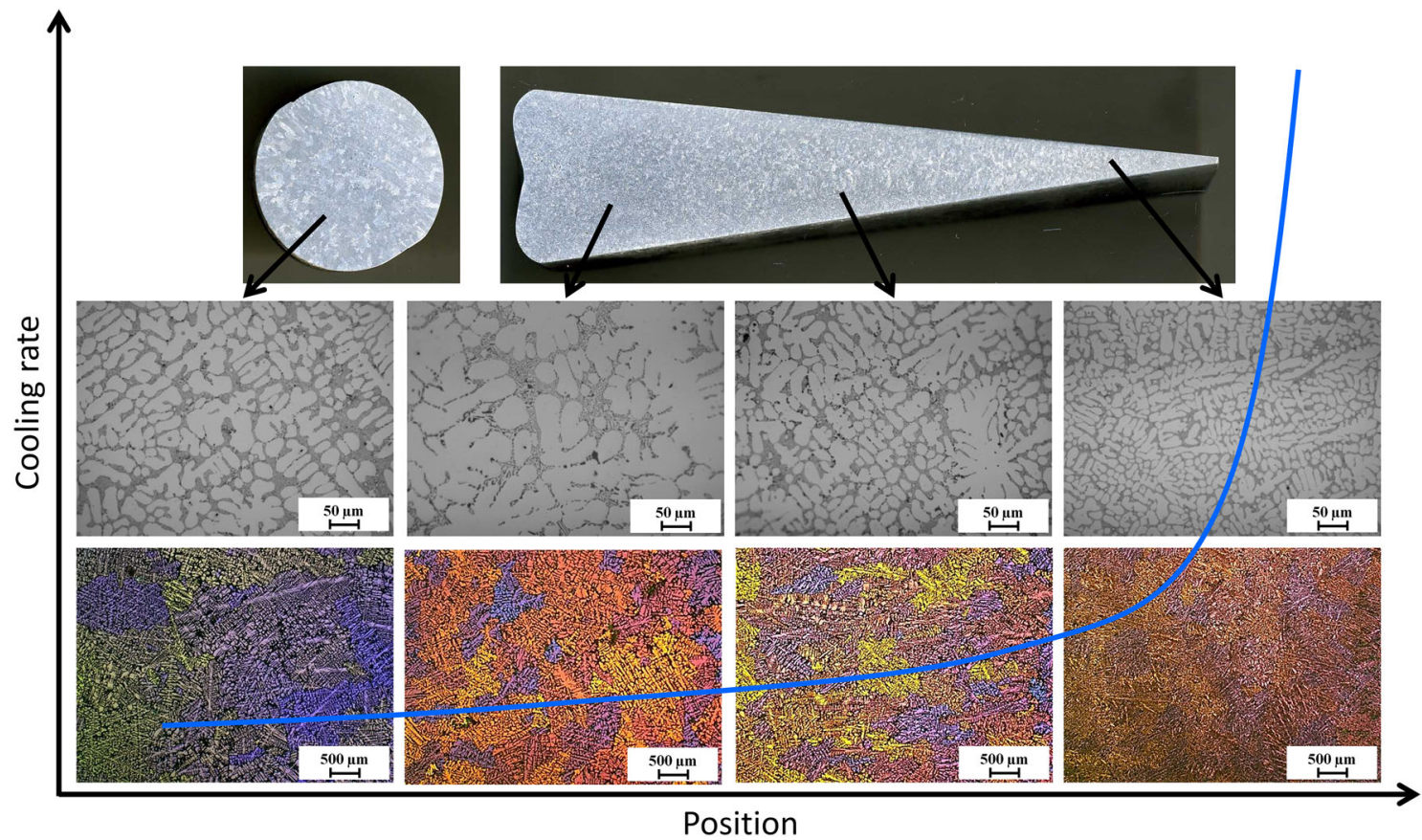

Fig. 3. Microstructural analysis results for the Al-Si alloy without the addition of the $\mathrm{Al}(96)-\mathrm{Nb}(2)-\mathrm{B}(2)$ master alloy.

$\mathrm{Al}(96)-\mathrm{Nb}(2)-\mathrm{B}(2)$ master alloy (Fig. 4) is selfexplanatory. Nevertheless, there are some points that should be stressed.

In the case of the reference (Fig. 3), as the cooling rate decreases the size of the aluminium grains (polarised light-coloured micrographs) increases significantly passing from hundreds of microns to millimetres. The fine grain microstructure at the tip of the wedge-shaped sample is due to the very fast heat extraction rate $(\sim 100 \mathrm{~K} / \mathrm{s}$ at the point where the micrograph was taken) and short solidification time of the thin section. The distribution of the second phase (silicon intermetallic) moves from rather homogeneously distributed amongst the fine dendritic arms (fast cooling) to rather inhomogeneous entrapment between the secondary arms of the dendrites. No comment can be made about the morphology of the secondary Si eutectic phase as the Al-Si alloy comes already modified (i.e. with the addition of strontium to change the morphology from plate-like to fibrous). ${ }^{25}$ These variations indicate that the nucleation process mainly depends on the way the heat is extracted from the solidification front and solute rejection. It is worth mentioning that columnar grains and the columnar/equiaxed transition zones are present in the reference material, especially at relatively slow cooling rates (i.e. cylindrical sample). After the addition of the $\mathrm{Al}(96)-\mathrm{Nb}(2)$ $\mathrm{B}(2)$ master alloy, it is clear that the grain structure is finer in each section (i.e. regardless of the cooling rate) and that the increment in the grain size with the decrement of the heat extraction rate is far less pronounced (Fig. 4) with respect to the reference material (Fig. 3). That is, the introduced Nb-based intermetallics actually act has heterogeneous nucleation sites for the $\alpha$-Al grains, enhancing their formation (grain refinement), making the solidification process less dependent on the heat extraction from the solidification front and solute rejection. A direct consequence of the finer structure of the aluminium grains is a more uniform distribution of the secondary phase due to the more even scattering of silicon when rejected from the solidification front or in the solute-rich pools remaining in interdendritic regions. Trace elements introduced into the melt via the use of the $\mathrm{Al}(96)-\mathrm{Nb}(2)-\mathrm{B}(2)$ master alloy also contribute to growth restriction during solidification. Nevertheless, their effect is not as critical, as in the 


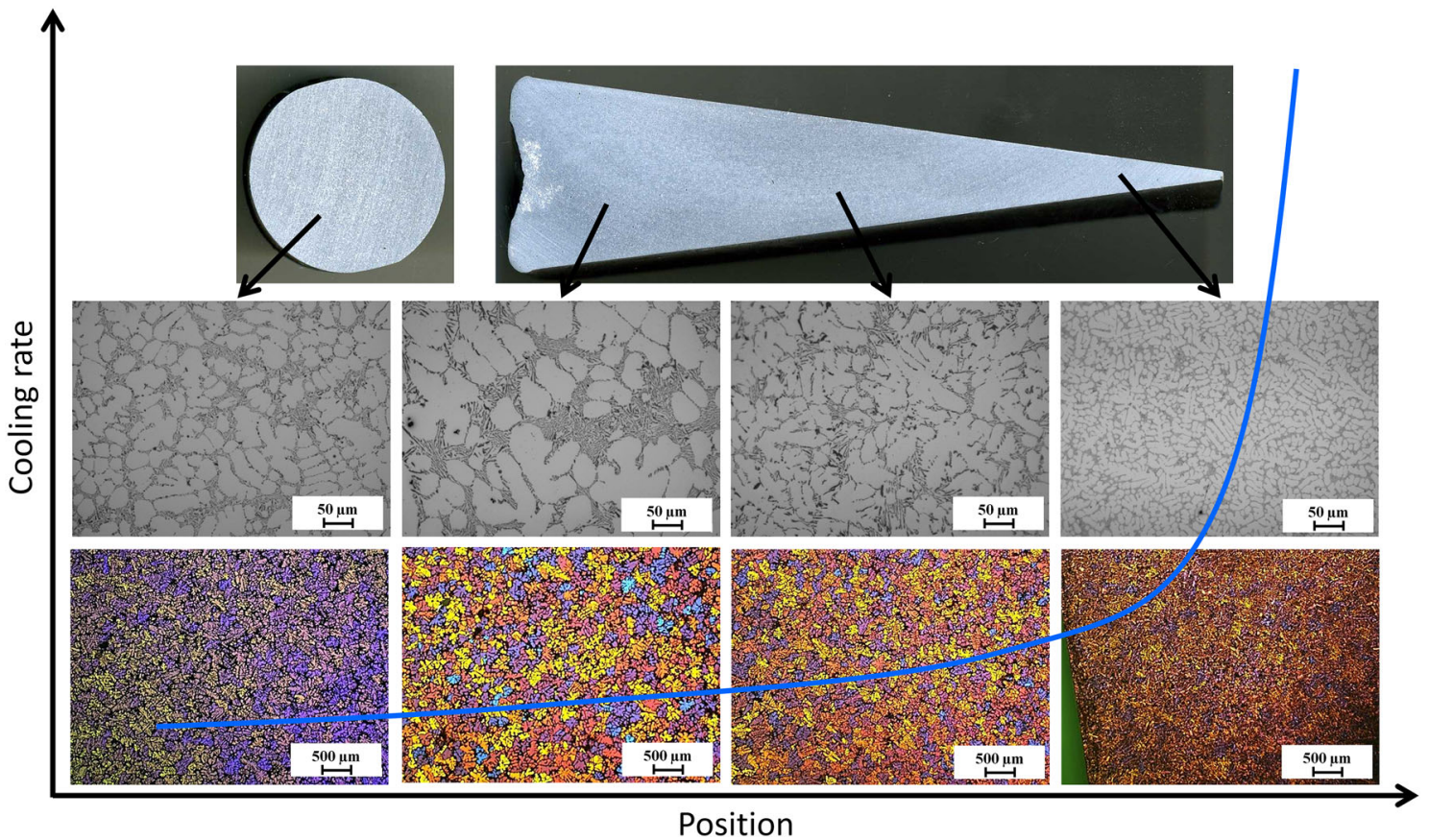

Fig. 4. Microstructural analysis results for the Al-Si alloy with the addition of the $\mathrm{Al}(96)-\mathrm{Nb}(2)-\mathrm{B}(2)$ master alloy.

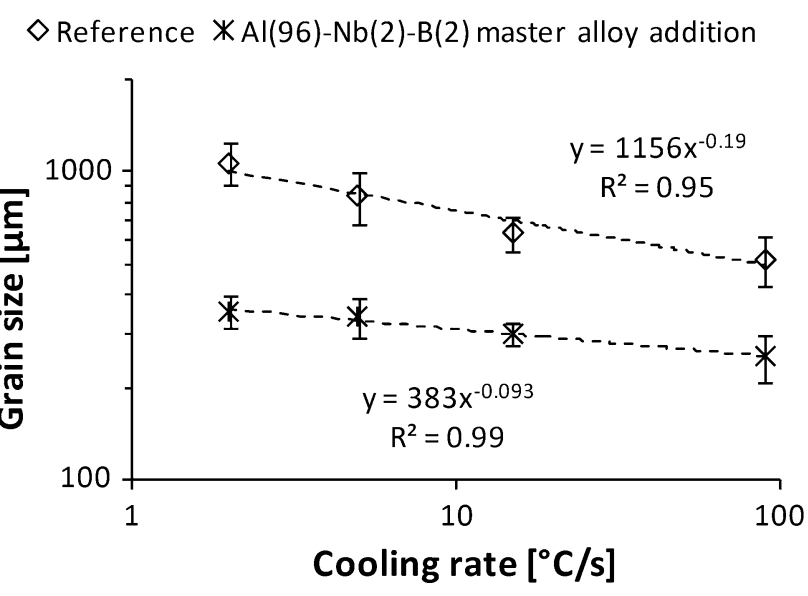

Fig. 5. Variation of the grain size as a function of the cooling rate.

case of refinement of pure aluminium, due to their relatively low contribution in comparison to the effect of amount alloying elements of the Al-8.4Si-0.3Mg$0.13 \mathrm{Fe}$ alloy. It is worth mentioning that the addition of the $\mathrm{Al}(96)-\mathrm{Nb}(2)-\mathrm{B}(2)$ master alloy did not affect the Si modification because the eutectic phase is still characterised by a fibrous morphology after grain refinement (Fig. 4). Finally, the enhanced heterogeneous nucleation promoted by the $\mathrm{Nb}$-based intermetallics suppresses the columnar/equiaxed transition zone in addition to the formation of columnar grains, especially at low cooling rates. The grain refining effectiveness of the $\mathrm{Nb}$-based intermetallics as a function of the cooling rate is shown in Fig. 5.
The trends of the grain size with respect to the cooling rate, shown in Fig. 5, are as expected from the microstructural analysis, and it was quantitatively proven that the difference between the Al-Si alloy grain size without and with the addition of the $\mathrm{Al}(96)-\mathrm{Nb}(2)-\mathrm{B}(2)$ master alloy decreases with increasing the cooling rate. This does not mean that the effectiveness of the Nb-based intermetallics in promoting heterogeneous nucleation decreases, rather that the heat extraction mechanism becomes more important for higher cooling rates. The plotting of the data in logarithmic scales (Fig. 5) gives as a result two linear straight lines and the experimental data from the microstructural analysis can reasonably be represented by power-law equations $\left(R^{2} \geq 0.95\right)$. On the basis of this equation, the grain size is proportional to the cooling rate although there are two experimental parameters that must be determined (i.e. grain size $=\beta \cdot($ cooling rate $^{n}$ ) where $\beta$ is the pre-exponential constant). It is worth mentioning that both $\beta$ and $n$ are composition-dependent. In the literature, it can be found that the distance between the arms of the primary dendrite depends on, apart from other physical parameters, the growth velocity and the temperature gradient. ${ }^{26}$ Assuming that there are no significant variations in the physical parameters (such as the Gibbs-Thomson coefficient) due to the addition of the $\mathrm{Al}(96)-\mathrm{Nb}(2)-\mathrm{B}(2)$ master alloy, the variation of the grain size can actually be estimated as proposed, with power-law equations. ${ }^{27}$ The lower $\beta$ and $n$ parameters of the alloy refined by means of the addition of the $\mathrm{Al}(96)-\mathrm{Nb}(2)-\mathrm{B}(2)$ master alloy is a further indication that the grain size and, thus, 
the nucleation/growth depends less on the thermal processing parameters and in particular the cooling rate.

\section{CONCLUSION}

In this study, micrometric Nb-based intermetallics were formed in situ in an $\mathrm{Al}(96)-\mathrm{Nb}(2)$ $B(2)$ master alloy in order to take advantage of their intrinsic characteristics such as low density and high-temperature stability. This work demonstrates that $\mathrm{Nb}$-based intermetallics can successfully be used to refine the microstructural features of $\mathrm{Al}-\mathrm{Si}$ alloys because they act as heterogeneous nucleation substrates and promote the formation and growth of $\alpha$-Al grains. This is possible because $\mathrm{Nb}$-based intermetallics present low lattice mismatch (30.6 and 4.2 for $\mathrm{NbB}_{2}$ and $\mathrm{Al}_{3} \mathrm{Nb}$, respectively) with the crystal structure of the aluminium grains. From the experimental results, it is concluded that the addition of $\mathrm{Nb}$-based intermetallics makes the solidification process and the corresponding microstructural features less sensitive to the cooling conditions as well as being much finer and more uniformly distributed.

\section{ACKNOWLEDGEMENT}

The authors are thankful for the financial support from the Technology Strategy Board (TSB) through the TSB/101177 Project and to the Engineering and Physical Sciences Research Council (EPSRC) through the EP/J013749/1 and EP/K031422/1 Projects.

\section{OPEN ACCESS}

This article is distributed under the terms of the Creative Commons Attribution 4.0 International License (http://creativecommons.org/licenses/by/4. $0 /$ ), which permits unrestricted use, distribution, and reproduction in any medium, provided you give appropriate credit to the original author(s) and the source, provide a link to the Creative Commons license, and indicate if changes were made.

\section{REFERENCES}

1. A.S. Cooper, E. Corenzwit, L.D. Inginotti, B.T. Matthias, and W.H. Zachariasen, Proc. Natl. Acad. Sci. USA 67, 313 (1970).

2. A. Yamamoto, C. Takao, T. Masui, M. Izumi, and S. Tajima, Phys. C 383, 197 (2002).

3. H. Takagiwa, E. Nishibori, N. Okada, M. Takata, M. Sakata, and J. Akimitsu, Sci. Technol. Adv. Mater. 7, 22 (2006).

4. C.-P. Reipt and G. Sauthotit, Intermetallics 3, 159 (1993).

5. C.-P. Reipt and G. Sauthotit, Intermetallics 4, 377 (1996).

6. G.K. Sigworth, Metall. Trans. A 15A, 277 (1984).

7. M.M. Guzowski, G.K. Sigworth, and D.A. Sentner, Metall. Trans. A 18A, 603 (1987).

8. T. Sritharan and H. Li, J. Mater. Process. Technol. 63, 585 (1997).

9. A.L. Greer, P.S. Cooper, M.W. Meredith, W. Schneider, P. Schumacher, J.A. Spittle, and A. Tronche, Adv. Eng. Mater. 5, 81 (2003).

10. B.J. Mc Kay and P. Schumacher, TMS 2005, 155-164 (2005).

11. P. Schumacher and B.J. Mc Kay, J. Non-Cryst. Solids 317, 123 (2003).

12. G.E. Totten and D.S. Mac Kenzie, Handbook of Aluminium vol. 2: Alloy Production and Materials Manufacturing (New York: Marcel Dekker Inc., 2003), p. 81.

13. S.A. Kori, V. Auradi, B.S. Murty, and M. Chakraborty, Mater. Forum 29, 387 (2005).

14. T.E. Quested, A.T. Dinsdale, and A.L. Greer, Mater. Sci. Technol. 22, 1126 (2006).

15. L. Bolzoni, M. Nowak, and N. Hari Babu, J. Alloys Compd. 623, 79 (2015)

16. M. Nowak, L. Bolzoni, and N. Hari Babu, Mater. Des. 66, 366 (2015).

17. L. Bolzoni, M. Nowak, and N. Hari Babu, Mater. Des. 66, 376 (2015).

18. Ihsan Barin, Thermochemical Data of Pure Substances (Weinheim: VCH Verlagsgesellschaft mbH, 1993), p. 1080.

19. Y. Birol, J. Alloys Compd. 513, 150 (2012).

20. B.S. Murty, S.A. Kori, and M. Chakraborty, Int. Mater. Rev. 47, 3 (2002).

21. D. Apelian, G.K. Sigworth, and K.R. Whaler, AFS Trans. 92, 297 (1984).

22. M. Easton and D.H.S. John, Metall. Mater. Trans. A 30A, 1625 (1999).

23. J.A. Spittle, Foundry Trade J. 181, 308 (2008).

24. D. Turnbull and B. Vonnegut, Ind. Eng. Chem. 44, 1292 (1952).

25. S.-Z. Lu and A. Hellawell, JOM 47, 38 (1995).

26. J.A. Dantzig and M. Rappaz, Solidification (Lausanne: EPFL Press, 2009), p. 324.

27. C. Merton, Flemings, Solidification Processing (New York: McGraw-Hill, 1974). 